\title{
УПРАВЛЕНИЕ ЭНЕРГОСБЕРЕЖЕНИЕМ И ПОВЫШЕНИЕМ ЭФФЕКТИВНОСТИ ЭНЕРГОСЕРВИСНЫХ КОНТРАКТОВ
}

\author{
(C) 2019 г. . Ю. Кириллова*, А. Ю. Королев **, Я. И. Понятова *** \\ *Российский экономический университет им. Г. В. Плеханова, г. Москва \\ **АО «ЭнергосбыТ Плюс», г. Москва \\ ***ООО «Юником Плюс», г. Москва
}

В статье проанализированы правовые основания заключения энергосервисных контрактов, раскрыто понятие энергосервисного контракта с точки зрения российского законодательства, рассмотрены виды энергосервисных контрактов, а также ключевые ресурсы, участвующие в прочессе подготовки и реализачии энергосервисных контрактов. Авторами обозначены актуальные ключевые изменения в действующем законодательстве в части прочесса заключения энергосервисных контрактов, и приведены примеры действий органов местного самоуправления в процессе их заключения. Исследована практика заключения энергосервисных контрактов со стороны заказчика, начиная от поиска потребностей, бюджетирования и заканчивая непосредственным заключением договора. Энергосервисный контракт рассмотрен с управленческой точки зрения как лучший способ повышения энергоэффективности и энергосбережения.

Ключевые слова: государственные и муниципальные закупки; закупки товаров, работ, услуг; энергосервисный контракт; энергосбережение; энергоэффективность.

The article analyzes legal basis for the conclusion of energy service contracts, reveals the concept of energy service contract from the point of view of the Russian legislation, considers the types of energy service contracts, as well as key resources involved in the process of preparation and implementation of energy service contracts. The authors identify current key changes in the current legislation of the process of energy service contracts, and examples of actions of local governments in the process of their conclusion. The practice of concluding energy service contracts on the part of the customer, starting from the search for needs, budgeting and ending with the direct conclusion of the contract. The energy service contract is considered from a management point of view as the best way to improve energy efficiency and energy saving.

Key words: state and municipal procurement; procurement of goods, works, services; energy service contract; energy saving; energy efficiency.

В процессе осуществления закупок товаров, работ и услуг для обеспечения энергоэффективности заказчик в соответствии с законодательством имеет право заключать энергосервисные контракты.

Их сфера охватывает:

- деятельность субъектов естественных монополий;
- услуги по водоснабжению, водоотведению, теплоснабжению, газоснабжению (за исключением услуг по реализации сжиженного газа, не используемого в качестве моторного топлива);

- услуги по подключению (присоединению) к сетям инженерно-технического обеспечения по регулируемым в соответствии 
с законодательством Российской Федерации ценам (тарифам);

- поставки электрической энергии, мазута, угля, топлива.

Суть энергосервисных контрактов состоит в комплексе действий, совершаемых исполнителем и направленных на повышение эффективности использования указанных энергетических ресурсов и энергосбережение.

Следует отметить, что в рамках энергосервисного контракта существует несколько форм сотрудничества [11]:

1) энергосервисный контракт заключается в целях экономии ресурсов и эксплуатационных затрат на основе повышения энергоэффективности и внедрения энергосберегающих технологий за счет инвестора;

2) заключение стандартного контракта с рассрочкой платежа - поставка и монтаж оборудования ведется за счет компании (возможность экономии без первоначальных вложений);

3) заключение оптимизационного контракта — в отличие от энергосервисного контракта энергоэффективные мероприятия выполняются и оплачиваются из расчетной экономии.

В каждом случае энергосервисный контракт представляет собой действенный способ повышения энергоэфективности.

К услугам энергосервисного контракта относятся:

1) модернизация котельного оборудования, внутреннего и наружного освещения, систем вентиляции, сжатого воздуха, отопления, кондиционирования, водо- и электроснабжения;

2) проектирование и реализация проектов по энергосбережению в различных отраслях;

3) внедрение систем учета (автоматизированные системы коммерческого учета электроэнергии розничного и/или оптового рынков, свободные двусторонние договора на поставку электроэнергии (мощности), устройств компенсации реактивной мощности, систем частотного регулирования, технологического оборудования меньшей мощности;

4) поставка энергосберегающего оборудования.

Таким образом, энергосервисный контракт - лучший способ энергосбережения в силу ряда причин [12]:
- позволяет повысить энергоэффективность на основе данных энергетического обследования в соответствии с Федеральным законом от 23.11.2009 г. №261-Ф3 «Об энергосбережении и о повышении энергетической эффективности, и о внесении изменений в отдельные законодательные акты Российской Федерации»;

- создает гибкие условия финансирования - отсутствие необходимости вкладывать собственные средства в закупку оборудования и проведение мероприятий;

- способствует повышению конкурентоспособности за счет снижения издержек на производство;

- инициирует модернизацию - происходит замена устаревших мощностей на современные, разработка и ввод энергоэффективного оборудования;

- предоставляет гарантированную величину экономии затрат на потребление энергоресурсов после своего исполнения.

Можно выделить несколько этапов заключения энергосервисного контракта через призму повышения энергоэффективности. Это энергоаудит, то есть комплексное энергетическое обследование; разработка программ энергосбережения; внедрение и реализация энергоэффективных мероприятий [5].

К основным видам энергоресурсов, энергоэффективность которых можно повысить при заключении энергосервисного контракта, относятся:

1) природный газ;

2) тепло;

3) вода;

4) электроэнергия;

5) прочие виды энергоресурсов (канализационные стоки, пар, сжатый кислород, сжатый воздух и др.).

Основными «потребителями», использующими данную форму сотрудничества, можно назвать:

- администрации муниципальных и городских округов (конечный потребитель население);

- предприятия ЖКХ (УК, ТСЖ) (конечный потребитель - население);

- peсурсоснабжающие организации (водоканалы, теплоснабжающие, газовые компании);

— крупные промышленные предприятия. 
Правительство Российской Федерации регламентирует начальную (максимальную) цену (НМЦ) контракта в соответствии Федеральным законом от 05.04.2013 г. №44-Ф3 «О контрактной системе в сфере закупок товаров, работ, услуг для обеспечения государственных и муниципальных нужд», которая не может превышать сумму фактических расходов заказчика на поставку энергетических ресурсов за предшествующий период (год). В конкурсной документации указывается цена лота энергосервисного контракта, в которую включаются расходы на поставки энергетических ресурсов по каждому виду товаров (услуг) и стоимость единицы каждого товара (услуги), а также [11]:

- фиксированный размер экономии расходов заказчика на поставки энергетических ресурсов в денежном выражении, максимальный процент указанной экономии, который может быть уплачен исполнителю в соответствии с энергосервисным контрактом;

- фиксированный процент экономии соответствующих расходов заказчика на поставки энергетических ресурсов, подлежащий уплате исполнителю в соответствии с энергосервисным контрактом, в денежном выражении, а также минимальный размер указанной экономии в денежном выражении;

- минимальный размер экономии в денежном выражении соответствующих расходов заказчика на поставки энергетических ресурсов, максимальный процент указанной экономии, который может быть уплачен исполнителю в соответствии с энергосервисным контрактом.

В случае, если энергосервисный контракт заключается путем проведения конкурса или запроса котировок, заказчик должен сформулировать в конкурсной документации одно из следующих предложений:

1) предложение о цене контракта или о проценте экономии;

2) предложение о сумме, определяемой как разница между соответствующими расходами заказчика на поставки энергетических ресурсов (начальной (максимальной) ценой контракта) и предложенной участником закупки экономией в денежном выражении указанных расходов заказчика;

3) предложение о сумме, определяемой как разница между соответствующими расхо- дами заказчика на поставки энергетических ресурсов (начальной (максимальной) ценой контракта) и экономией в денежном выражении указанных расходов заказчика, предложенной участником закупки и уменьшенной на стоимостную величину, соответствующую предложенному участником закупки проценту такой экономии.

Заключение энергосервисного контракта в форме электронного аукциона подразумевает снижение одного из показателей, указанных выше. Лицо, сделавшее предложение о наиболее низкой сумме, признается победителем запроса котировок. Условия исполнения энергосервисного контракта оценивается конкурсной комиссией. При этом сопоставляются предложение о сумме расходов заказчика на поставки энергетических ресурсов, осуществляемые в результате заключения (исполнения) энергосервисного контракта, и расходы, которые он (заказчик) понесет по энергосервисному контракту.

Цена, по которой заключается энергосервисный контракт, определяется как [11]:

1) фиксированный процент экономии в денежном выражении соответствующих расходов заказчика на поставки энергетических ресурсов, предложенный участником закупки, с которым заключается такой контракт;

2) фиксированный процент экономии в денежном выражении соответствующих расходов заказчика на поставки энергетических ресурсов, предложенный участником закупки, с которым заключается такой контракт;

3) процент экономии в денежном выражении соответствующих расходов заказчика на поставки энергетических ресурсов, предложенный участником закупки, с которым заключается такой контракт.

В содержании энергосервисного контракта указывается экономия соответствующих расходов заказчика на поставки энергетических ресурсов в натуральном выражении по каждому виду таких ресурсов. Данная экономия рассчитывается на основании фиксированного размера экономии в денежном выражении или экономии в денежном выражении, предложенной участником закупки, а также стоимости единицы каждого товара, работы или услуги, которая указывается в конкурсной документации, документации 
об электронном аукционе, извещении о проведении запроса котировок.

В энергосервисном контракте также указывается процент экономии соответствующих расходов заказчика на поставки энергетических ресурсов, предложенный участником закупки, или фиксированный процент такой экономии, который не меняется в ходе исполнения этого контракта. В документации о закупке заказчик определяет размер обеспечения по исполнению энергосервисного контракта, который колеблется от пяти до тридцати процентов либо фиксированного процента минимального размера экономии в денежном выражении расходов заказчика на поставки соответствующих энергетических ресурсов, подлежащего уплате исполнителю энергосервисного контракта; либо максимального процента минимального размера экономии в денежном выражении соответствующих расходов заказчика на поставки энергетических ресурсов, который может быть уплачен исполнителю. При этом под обязательством исполнителя энергосервисного контракта понимается обеспечение предусмотренной контрактом экономии в натуральном выражении соответствующих расходов заказчика на поставки энергетических ресурсов без учета экономии в стоимостном выражении.

Оплата энергосервисного контракта зависит от размера экономии расходов заказчика на поставки энергетических ресурсов, а также от процента экономии, определенной в стоимостном выражении по ценам (тарифам) на соответствующие энергетические ресурсы, фактически сложившимся за период исполнения контракта.

Одними из наиболее масштабных заказчиков энергосервисных контрактов выступают органы местного самоуправления. Формирование местного бюджета городского или муниципального образования осуществляется исполнительными органами местного самоуправления в соответствии с Бюджетным кодексом Российской Федерации от 31.07.1998 г. №145-Ф3 [2]. Консолидированный бюджет субъекта РФ представляет следующую структуру:
1) бюджет субъекта РФ;
2) местные бюджеты:
- городские округа;
- районы;
- поселения.

Проект бюджета субъекта РФ составляется и утверждается сроком на три года (очередной финансовый год и плановый период). Проект бюджета муниципального/городского образования составляется и утверждается сроком на один год (на очередной финансовый год) или сроком на три года в соответствии с муниципальными нормативно-правовыми актами [9].

Бюджетный процесс в муниципальных образованиях в обобщенном виде делится на четыре этапа (таблица 1).

Перед заключением энергосервисного контракта проводится анализ потребностей:

Этапы бюджетного процесса

Таблица 1

\begin{tabular}{|l|c|l|}
\hline \multicolumn{1}{|c|}{ Этап } & \multicolumn{1}{|c|}{ Срок* } & \multicolumn{1}{c|}{ Уполномоченный орган } \\
\hline $\begin{array}{l}\text { Составление } \\
\text { проекта бюджета }\end{array}$ & $01.06 . \mathrm{x}-31.10 . \mathrm{x}$ & $\begin{array}{l}\text { Администрация муниципального/ } \\
\text { городского образования }\end{array}$ \\
\hline $\begin{array}{l}\text { Рассмотрение } \\
\text { и утверждение бюджета }\end{array}$ & $01.11 . \mathrm{x}-31.12 . \mathrm{x}$ & $\begin{array}{l}\text { Представительный орган муниципаль- } \\
\text { ного/городского образования }\end{array}$ \\
\hline Исполнение бюджета & $01.01 . \mathrm{x}+1-31.12 . \mathrm{x}+1$ & $\begin{array}{l}\text { Финансовый орган муниципального/ } \\
\text { городского образования }\end{array}$ \\
\hline $\begin{array}{l}\text { Отчет об исполнении } \\
\text { бюджета }\end{array}$ & До 01.05.x +1 & $\begin{array}{l}\text { Глава администрации муниципально- } \\
\text { го/городского образования }\end{array}$ \\
\hline $\begin{array}{l}\text { *Точные сроки определяются локальными нормативно-правовыми актами каждого муници- } \\
\text { пального/городского образования [5]. }\end{array}$ \\
\hline
\end{tabular}


1. Освещение:

1.1. Замена светильников, опор, средств индивидуального освещения.

1.2. Установка шкафов управления.

2. Теплоснабжение и водоснабжение:

2.1. Замена сетей холодного водоснабжения, установка узлов учета.

2.2. Замена насосного оборудования.

2.3. Установка систем автоматики и диспетчеризации.

3. Водоотведение:

3.1. Замена насосного оборудования.
3.2. Замена аэраторов, компрессоров, установка систем автоматики.

Анализ источников финансирования муниципального/городского образования схематично представлен в таблице 2.

После завершения анализа источников финансирования муниципального/городского образования проводится анализ предложений контрагента (таблица 3).

Общий процесс стадий реализации энергосервисного контракта в случае, если органы местного самоуправления выступают

Источники финансирования

Таблица 2

\begin{tabular}{|c|c|}
\hline Источник & Условия \\
\hline $\begin{array}{l}\text { Государственные программы - энерго- } \\
\text { сбережение и повышение энергетической } \\
\text { эффективности до } 2020 \text { года }\end{array}$ & $\begin{array}{l}\text { Реконструкция/строительство/модернизация: } \\
\text { - наличие проектно-сметной документации; } \\
\text { - целевые, однолетние денежные средства; } \\
\text { - соблюдение требований законодательства; } \\
\text { - софинансирование проекта; } \\
\text { - наличие ценовой экспертизы. }\end{array}$ \\
\hline $\begin{array}{l}\text { Резервный фонд - часть средств, предна- } \\
\text { значенная для исполнения расходных обя- } \\
\text { зательств в случае недостаточности дохо- } \\
\text { дов областного бюджета для финансового } \\
\text { обеспечения расходных обязательств }\end{array}$ & $\begin{array}{l}\text { Реконструкция/строительство: } \\
\text { - наличие проектно-сметной документации; } \\
\text { - целевые, однолетние денежные средства; } \\
\text { - соблюдение требований законодательства; } \\
\text { - ликвидация чрезвычайных ситуаций; } \\
\text { - наличие ценовой экспертизы. }\end{array}$ \\
\hline $\begin{array}{l}\text { Расходные полномочия органов местно- } \\
\text { го самоуправления - выполнение рас- } \\
\text { ходных обязательств за счет собственных } \\
\text { доходов, то есть доходов без учета субвен- } \\
\text { ций другого уровня власти }\end{array}$ & $\begin{array}{l}\text { Реконструкция/строительство/модернизация/ } \\
\text { ремонт: } \\
\text { - наличие сметной документации; } \\
\text { - возможность заключения долгосрочных } \\
\text { контрактов; } \\
\text { - соблюдение требований } 44 \text { ФЗ, бюджетного } \\
\text { кодекса. }\end{array}$ \\
\hline
\end{tabular}

Анализ предложений контрагента

\begin{tabular}{|l|l|}
\hline $\begin{array}{l}\text { Проекты по энергосбережению и повышению } \\
\text { энергетической эффективности }\end{array}$ & - наличие экономического эффекта \\
\hline Планирование бюджета на 3 года & $\begin{array}{l}\text { - начало работ в } 2017 ; \\
\text { - окончание работ в } 2019\end{array}$ \\
\hline $\begin{array}{l}\text { Источник оплаты — увеличение расходных } \\
\text { полномочий клиентов на } 3 \text { года }\end{array}$ & $\begin{array}{l}\text { - формирование трехлетнего бюджета для } \\
\text { - расчет размера увеличенных расходных } \\
\text { полномочий }\end{array}$ \\
\hline
\end{tabular}


в роли заказчика, представляет собой следующие этапы.

1. Предложение контрагента.

1.1. Предоставление финансирования с учетом возврата денежных средств.

1.2. Бесплатная проработка проектов, направленных на энергосбережение и повышение энергетической эффективности.

2. Органы исполнительной власти субъекта федерации.

2.1. Утверждение приказа об определении пилотных муниципальных образований.

2.2. Организация рабочих совещаний муниципалитетов с контрагентами.

3. Муниципалитеты субъекта федерации.

3.1. Формирование пакетов документов для участия (сметный расчет, расчет экономического эффекта, обоснования необходимости реализации проекта).

3.2. Расчет размера увеличенных расходных полномочий.

4. Органы исполнительной власти субъекта федерации.

4.1. Согласование проектов.

4.2. Заключение соглашений об увеличении расходных полномочий.

5. Муниципалитеты субъекта федерации.

5.1. Внесение изменений в бюджет с учетом оплаты по контрактам.

5.2. Совместная с контрагентом организация закупочных процедур.

6. Контрагент - реализация проекта.

Ключевые изменения в действующем законодательстве в части процесса заключения энергосервисных контрактов сводятся к следующему:

1) часть 13.1 в статью 34 введена в №44-Ф3 от 01.05.2017 г. №83-Ф3 (в ред. Федерального закона от 01.05.2019 г. №71-Ф3) - срок оплаты заказчиком поставленного товара, выполненной работы (ее результатов), оказанной услуги, отдельных этапов исполнения контракта должен составлять не более 30 дней с даты подписания заказчиком документа о приемке [11];

2) утверждение Постановления Правительства РФ от 15.05.2017 г. №570, предусматривающего, что с 01.08.2018 г. выполнение работ собственными силами должно быть не менее $25 \%$ [6].

Указанные меры направлены на стимулирование субъектов малого и среднего предпринимательства [3].
На государственном уровне в Российской Федерации поставлена стратегическая задача снижения на 40\% энергопотребления всех зданий бюджетной сферы Российской Федерации до 2020 года, что потребует огромного финансирования, исчисляемого миллиардами рублей. Одним из вариантов решения поставленной задачи является энергосервисный контракт как ключевой способ повышения энергоэффективности, наиболее прозрачный, удобный и конкурентоспособный рыночный механизм. Как следствие, во многих муниципальных субъектах Российской Федерации энергосервисные контракты успешно реализуются. Перспективность данного направления бизнеса заключается в первую очередь в том, что снижение затрат - весьма привлекательная цель как для организаций, так и для физических лиц. Кроме того, государство на законодательном уровне рекомендует позаботиться об энергосбережении и об энергоэффективности, и реализация указанных мероприятий положительно скажется также на рейтинге и имиджевой составляющей органов муниципальной власти.

\section{Литература}

1. Белокрылова О.С., Гуичелюк Е.Ф., Вольчик В.В., Филоненко Ю.В., Бутова С.В., Белокрылов К.А., Корытиев М.А. Нормативно-законодательная база для изучения курса «Управление государственными и муниципальными закупками». Часть 1. Закон №44-Ф3. - Ростовна-Дону, 2015. - 304 с.

2. Бюджетный кодекс Российской Федерации от 31.07.1998 г. №145-Ф3 (ред. от 15.04.2019 г.). — [Электронный ресурс] Режим доступа: http://www.consultant.ru/ document/cons_doc_LAW_19702/. (Дата обращения: 10.06.2019 г.).

3. Готовое решение: Можно ли привлекать субподрядчиков для исполнения государственных контрактов (КонсультантПлюс, 2019). - [Электронный ресурс] Режим доступа: http://www.consultant. $\mathrm{ru} /$ cons/cgi/online.cgi? $\mathrm{req}=$ doc $\&$ base $=\mathrm{CJI}$ $\& n=114137 \# 06498671469669275$. (Дата обращения: 10.06.2019 г.).

4. Готовое решение: Как действовать заказчику в ходе исполнения контракта по Закону №44-Ф3. - [Электронный ресурс] - 
Режим доступа: http:/www.consultant.ru/ cons/cgi/online.cgi? req $=$ doc $\&$ base $=$ PKBO $\& n=36836 \# 0027102160136186937$. (Дата обращения: 10.06.2019 г.).

5. Обзор административной практики в сфере размещения заказов для государственных и муниципальных нужд. - [Электронный ресурс] — Режим доступа: http:// www.consultant.ru/cons/cgi/online.cgi?req=do c\&base $=$ CJI\&n=115706\#06304245141446285. (Дата обращения: 10.06.2019 г.).

6. Постановление Правительства РФ от 15.05.2017 г. №570 (ред. от 20.11.2018 г.) «Об установлении видов и объемов работ по строительству, реконструкции объектов капитального строительства на территории Российской Федерации, которые подрядчик обязан выполнить самостоятельно без привлечения других лиц к исполнению своих обязательств по государственному и (или) муниципальному контрактам, и о внесении изменений в Правила определения размера штрафа, начисляемого в случае ненадлежащего исполнения заказчиком, поставщиком (подрядчиком, исполнителем) обязательств, предусмотренных контрактом (за исключением просрочки исполнения обязательств заказчиком, поставщиком (подрядчиком, исполнителем), и размера пени, начисляемой за каждый день просрочки исполнения поставщиком (подрядчиком, исполнителем) обязательства, предусмотренного контрактом». - [Электронный ресурс] — Режим доступа: https://base.garant.ru/71675760/. (Дата обращения: 24.06.2019 г.).

7. Письмо Минфина России от 2 ноября 2017 г.№24-03-08/72382 «О рассмотрении обращения». - [Электронный ресурс] - Peжим доступа: https://www.garant.ru/products/ ipo/prime/doc/71750804/. (Дата обращения: 24.06.2019 г.).

8. Письмо Минфина России от 26 октября 2017 г. №24-03-08/70438 «О рассмотрении обращения». - [Электронный ресурс] - Peжим доступа: https:/www.garant.ru/products/ ipo/prime/doc/71700520/. (Дата обращения: 24.06.2019 г.).

9. Титова Г.Г. Регламентированный комплекс по исполнению контракта на поставку товаров для государственных и муниципальных нужд. - [Электронный ресурс] Режим доступа: http:/отрасли-права.рф/ article/24664. (Дата обращения: 10.06.2019 г.).

10. Федеральный закон «О защите конкуренции» от 26.07.2006 г. №135-Ф3 (ред. от 29.07.2018 г.). - [Электронный ресурс] Режим доступа: http://www.consultant.ru/ document/cons_doc_LAW_61763/. (Дата обращения: 24.06.2019 г.).

11. Федеральный закон от 05.04.2013 г. №44-Ф3 (ред. от 01.05.2019 г.) «О контрактной системе в сфере закупок товаров, работ, услуг для обеспечения государственных и муниципальных нужд» (с изм. и доп., вступ. в силу с 12.05.2019 г.). — [Электронный ресурс] - Режим доступа: https://fzakon.ru/ laws/federalnyy-zakon-ot-05.04.2013-n-44-fz/. (Дата обращения: 10.06.2019 г.).

12. Сайт компании ООО «ЕЭС-Гарант». [Электронный ресурс] - Режим доступа: https://www.ies-garant.ru/. (Дата обращения: 14.06.2019 г.). 


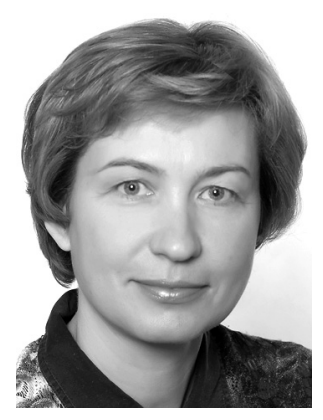

Кириллова Оксана Юрьевна - доктор экономических наук, доцент Российского экономического университета им. Г.В. Плеханова.

Kirillova Oksana Yurevna - Doctor of economic sciences, associate professor of Plekhanov Russian University of Economics.

117997, г. Москва, Стремянный пер., 36

36 Stremyannyj pereulok, 117997, Moscow, Russia

Тел.: 8 (916) 652-52-52; e-mail: cg_123@mail.ru

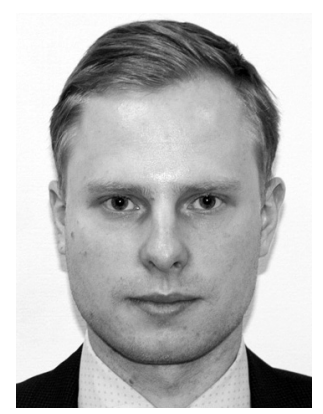

Королев Артем Юрьевич - руководитель Управления ценообразования АО «ЭнергосбыТ Плюс», магистрант Российского экономического университета им. Г.В. Плеханова.

Korolyov Artyom Yurievich - Head of Department of Price Formation of JSC «EnergosbytPlus» (CJCS «TPlus»), Undergraduate of Plekhanov Russian University of Economics.

117997, г. Москва, Стремянный пер., 36

36 Stremyannyj pereulok, 117997, Moscow, Russia

Тел.: 8 (916) 652-52-52; e-mail: korolyov-artyom@yandex.ru

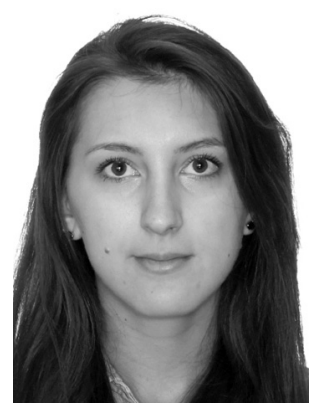

Понятова Яна Игоревна - кредитный менеджер ООО «Юником Плюс», магистрант Российского экономического университета им. Г. В. Плеханова.

Ponyatova Yana Igorevna - Credit manager of «Yunikom plyus» LTD, Undergraduate of Plekhanov Russian University of Economics.

117997, г. Москва, Стремянный пер., 36

36 Stremyannyj pereulok, 117997, Moscow, Russia

Тел.: 8 (916) 652-52-52; e-mail: ponyatova.y@gmail.com 